\title{
Investigating the Problems and Proposing Solutions for Rural Residential Buildings in Northwest China
}

\author{
Zhaobo Zhang1*, Jianqiang Wang'2, Mao $\mathrm{Hu}^{3}$ \\ ${ }^{1}$ Department of Civil Engineering, Gansu Agricultural University, Lanzhou 730070, Gansu Province, China \\ ${ }^{2}$ Gansu Wande Green Building Co., Ltd., Pingliang 743400, Gansu Province, China \\ ${ }^{3}$ Pingliang Mechanical and Electrical Engineering School, Pingliang 743400, Gansu Province, China \\ *Corresponding author: Zhaobo Zhang, Zhaobo0128@hotmail.com
}

Copyright: () 2022 Author(s). This is an open-access article distributed under the terms of the Creative Commons Attribution License (CC BY 4.0), permitting distribution and reproduction in any medium, provided the original work is cited.

\begin{abstract}
With the increasing income of the rural population in Northwest China, people's sense of happiness and gain is also increasing. However, the improvement of housing conditions is lagging behind the increasing income levels. In recent years, the government and owners have paid much attention to this issue. The local government has successively issued relevant guidelines and policies to encourage owners to reconstruct their houses and improve their housing conditions. Before improving housing conditions, the existing housing problems must be identified. In order to have a comprehensive and indepth understanding of the problems of rural residential buildings in Northwest China and to propose corresponding solutions, 90 representative rural residential buildings of three provinces in Northwest China have been selected for investigation, and mass data have been obtained. Upon analyzing these data, it has been found that there are problems in five aspects of rural residential buildings in Northwest China: architectural style and functional space layout, energy utilization and dissipation, design, construction, as well as structural safety and seismic measures. Valid solutions are proposed to address these problems, which can also provide a reference for the government and enterprises engaged in the architecture, engineering, and construction (AEC) industry in rural areas.
\end{abstract}

Keywords: Investigation; Problems; Rural residential buildings; Solutions

Online publication: March 4, 2022

\section{Introduction}

With the rapid development of China's economy, the rural areas in Northwest China have undergone great changes, and the living standards of people there have greatly improved ${ }^{[1]}$. However, the progress of rural residential buildings (RRB) is lagging behind the economic development, whereas people's requirements for living conditions are increasing ${ }^{[2]}$. Many problems exist throughout the life cycle of RRB ${ }^{[3]}$, such as similar architectural style, unreasonable structural configuration and components arrangement, poor thermal insulation performance, and excessive heat dissipation. The government is actively looking into countermeasures to improve the quality and level of RRB. For example, in Gansu Province, the government issued a three-year plan for the reformation of RRB (2018-2020). According to this plan, all dilapidated RRB in Gansu Province must be reformed by the end of 2020. Effective reform measures are based on indepth understanding and accurate analysis of the existing problems. Therefore, in order to discern the 
problems existing in RRB in Northwest China and propose effective solutions, so as to provide a reference for the government and enterprises who are engaged in the AEC industry in rural areas, an investigation on 90 RRB (90 samples) in 9 counties in Gansu Province, Ningxia Hui Autonomous Region, and Shaan Xi Province in Northwest China have been carried out, and mass data have been obtained. After analyzing the data, it is found that there are five types of problems of RRB in terms of architectural style and functional space layout, design, construction, energy utilization and dissipation, as well as structural safety and seismic measures. Constructive solutions, aiming at above problems, are proposed in this paper. This paper is arranged as follows: the discussion on investigation plan, followed by the investigation results and the problems; the fourth part discusses the solutions, and the conclusion is presented in the final section.

\section{Investigation plan}

\subsection{Investigation content}

\subsubsection{Overall situation of the residents and their RRB}

The investigation of this theme consists of four parts.

(1) The overall architectural style and the characteristic architectural style.

(2) The family status and the basic information of selected RBB.

(3) The layout of RRB in yard and the functional space layout of RRB.

(4) The reform demands of the residents.

\subsubsection{Energy utilization and dissipation}

This part comprises of thermal source, cooking heat source, materials and heat-insulation technology of walls, roofs, and windows, as well as the utilizing situation of renewable energy technology.

\subsubsection{Design}

This part aims to investigate whether the selected RRB has been designed properly.

\subsubsection{Construction}

This part aims to evaluate the professionalism of construction workers and construction technologies.

\subsubsection{Structural safety and seismic measures}

This part aims to investigate the structural configuration of RRB and the problems in RRB components. The seismic measures of RRB will also be evaluated.

\subsection{Investigation method}

The investigation methods included interviews, measurements, questionnaires, sketches, and data analysis. The interviewees comprised of two groups: officers from Housing and Urban-Rural Development Bureau (Figure 1), and the village committee staffs and owners of investigated RRB (Figure 2). The measurements included ruler measurement and UAV measurement. The designed questionnaires were filled by the owners during the interview, while the house plan and elevation of RRB was drawn by the investigators by hand. For data analysis, drawings and information from the interview were first collated; then, the questionnaire data were entered into the database, and finally, analysis was done. 


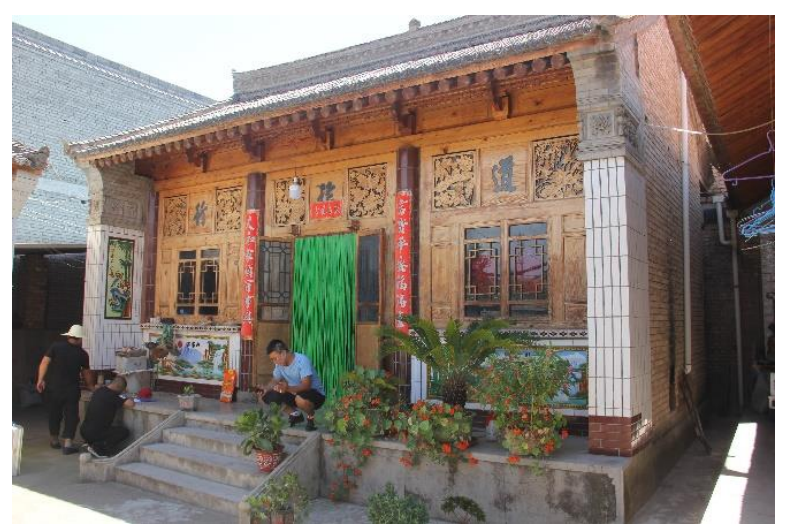

Figure 1. Interviewing the officers

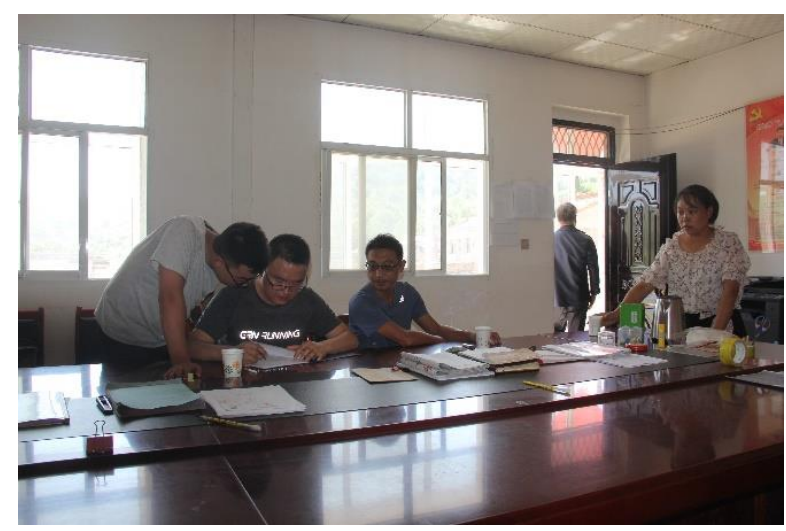

Figure 2. Interviewing the owners

\section{Investigation results}

\subsection{Family status and overall situation of RRB}

Among the samples, $69.5 \%$ have a household size of more than 5 people. Samples with per capita living area less than 25 square meters accounted for $38.6 \%$, which is far less than the national average per capita living area of 40.8 square meters ${ }^{[4]}$. The source of family income is mainly from farming and out-migrant work, in which the proportion is $53.5 \%$. In terms of construction time and the willingness to reconstruct, $37.8 \%$ of the samples have been built before 2000 , and $40 \%$ of the owners have the aspiration to reconstruct their houses.

From the perspective of architectural style and feature, the construction materials of RRB built in the past 10 years were mainly reinforced concrete and masonry, resulting in monotonic architectural styles and a high degree of similarity. However, preserved architectural styles that represent regional cultural characteristics (Figure 3 and Figure 4) face the risk of being lost. The reason is that in the mind of the majority of owners, the RRB constructed with soil and wood, which have been used for several generations, no longer conform to the characteristics of the current era. With the increasing income of owners, the unwillingness to use outdated soil and wood as construction materials is more prevalent; instead, they are more willing to use stronger and modern brick-concrete and cast-in-place reinforced concrete structures.

In terms of functional space layout, halls are habitually used as central functional space, bedrooms, kitchens, utility rooms, etc. Sometimes, they are endowed with various functions, including reception, cooking, dining, and living, at the same time, which is far beyond their functional load. The spatial arrangement of different functional areas reflects casualness. For example, agricultural production space and residential space are interlaced, while private space and public space are used interchangeably. In addition, samples that show a loss of function, such as those that do not have space for daily personal cleanliness, can only be arranged arbitrarily at the corridors or aisles.

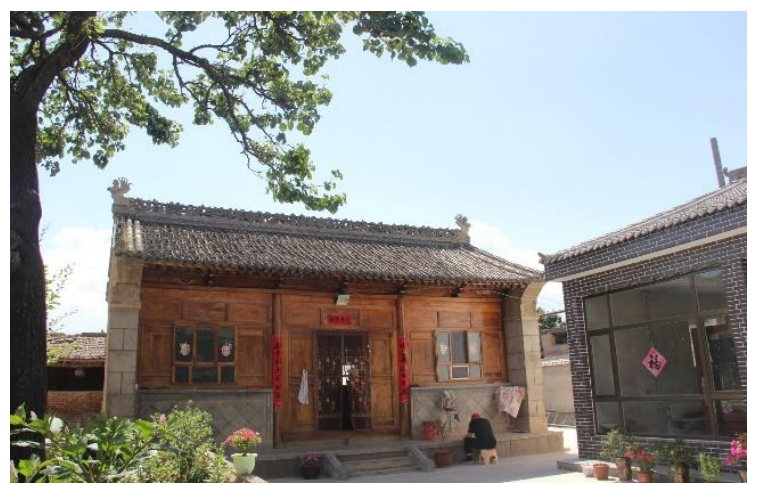

Figure 3. RRB with cultural characteristics

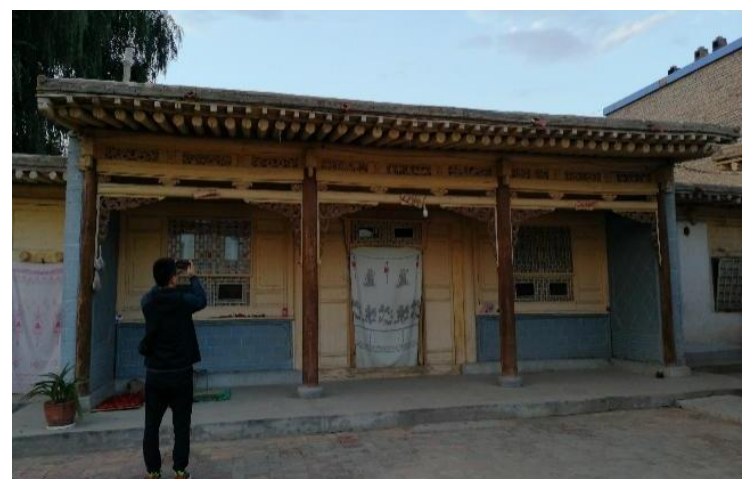

Figure 4. RRB with cultural characteristics 


\subsection{Energy utilization and dissipation}

Among all the samples, only $3.6 \%$ have thermal insulation measures. In evaluating the air tightness of doors and windows, three different levels were used: "good," "okay," and "poor." Doors with "okay" air tightness accounted for $43.4 \%$, while those with "poor" air tightness accounted for $48.2 \%$; windows with "okay" air tightness accounted for $55.3 \%$, while those with "poor" air tightness accounted for $34.1 \%$. Overall, the thermal insulation effect of RRB is not optimistic. The energy for cooking is mainly from coal and firewood, accounting for $34.5 \%$ and $66.7 \%$, respectively. Among the samples, $88.4 \%$ use coal and "soil kang" (a kind of bed, made of adobe) as their heating source in winter. During the investigation, only one renewable energy source (solar energy) is found, which is used for bathing. The proportion of RRB equipped with solar bathing device is $38.4 \%$.

In general, coal is the main energy source of RRB. The amount of energy usage and heat dissipation of RRB is high owing to its inefficient heating systems, extensive energy using patterns, outdated construction techniques, large shape coefficient, and wrong floor plans. The reasons for these problems are discussed below.

(1) The awareness of energy conservation among the owners and construction workers is poor as they do not possess knowledge of energy-saving techniques. The thermal insulation measures of walls, roofs, and windows are only based on previous construction experiences. The lack of theoretical and technical support results in serious energy waste and poor energy-saving effect of RRB.

(2) The high thermal conductivity of envelope material leads to bad thermal insulation performance. "Okay" or "poor" air tightness of most doors and windows as well as the unqualified thickness of the outer wall of most samples result in serious heat loss.

(3) The usage rate of renewable energy is very low. In addition to solar energy, terrestrial heat energy, biomass energy, and wind energy suitable for architecture heating have not been utilized.

\subsection{Design}

In terms of design, $89 \%$ of the samples have been designed by the owners themselves (namely, independent design), with only $6.1 \%$ being designed by design companies. Independent design means that there is no design drawings or formal design drawings to guide the construction. The design drawings of RRB are derived from two sources: (1) general-purpose drawing set; (2) drawings designed by formal design companies. No owners are willing to buy drawings from design companies because the fees are far beyond their expectations when the total investment exceeds 200,000 yuan. If the general-purpose drawing set is used, it will probably be revised by the owner during the construction stage. In this case, safety, function, and livability of RRB will all be affected, which is unacceptable from a professional perspective. From the owner's point of view, the revision of the general-purpose drawing set is reasonable because the types of drawings are limited, and they do not meet the needs of every owner. In addition, the safety coefficient of the general-purpose drawing set usually takes a large value, so the amount of steel bars and concrete will increase, and the cost will exceed the owner's expectations.

\subsection{Construction}

There are two types of teams that are involved in RRB construction. The first team consists of the owner's family members, relatives, and neighbors, accounting for $66.7 \%$. The other team consists of small contractor teams that are active in the rural construction market in recent years to carry out all-contract or half-contract construction work, accounting for $33.3 \%$. These two types of teams are usually temporarily formed, without qualifications, construction drawings, and professional technicians. They are not systematically trained, and they only have minimal understanding about structural stress, quality management, and geological conditions. The seismic requirement and rule of fire protection may be 
neglected. In addition, their construction technology is not professional or systematic, relying entirely on experience, or even copying the working flow of other companies. In that case, the quality and safety of construction projects cannot be guaranteed. At times, potential safety hazards occur when the owner conducts construction site selection. For example, due to space limitations and construction misconceptions, the possibility of constructing RRB in areas with poor geology or instigating large changes in topography may occur. Some construction teams do not properly treat the foundation or do not even treat the foundation before construction; at times, the treatment materials used are quite simple, which will lead to problems, such as uneven settlement of foundation.

With the acceleration of urban-rural integration process, restaurants, agritainment tourism, homestay inns, and other consumption industries are rising in rural areas ${ }^{[5]}$. Many owners have renovated their houses and rechristened them as business premises, adding floors and expanding their houses as they wish. Voluntary removing the walls and drilling holes by the owners themselves are commonly seen.

\subsection{Structural safety and seismic measures}

Among all the samples, RRB in the form of "masonry-concrete" structure is the most common, accounting for $53.7 \%$, followed by "masonry-wood," "masonry-soil," and "soil-wood" structures. "Masonry-soil" structure refers to structure with walls made of raw soil and masonry. It includes three forms: "front masonry and back soil," "top soil and bottom masonry," "one side masonry and three sides soil." The inconsistency in structural form weakens the occlusal relationship between vertical and horizontal walls, which eventually leads to wall cracking even the collapse of the structure. Samples with seismic measures accounted for $52.3 \%$, whereas samples without seismic measures accounted for $47.7 \%$. Seismic measures here mainly refer to ring beams and constructional columns, which only appear in masonry-concrete structure.

Wall cracking and the regaining of moisture in the walls and foundation are the most common problems of RRB. These problems are caused by improper treatment during construction or interior decoration. For example, poor-quality waterproofing leads to downward infiltration of rainwater, causing the walls to regain moisture. At times, due to poor construction quality of a foundation, groundwater infiltrates upward and is absorbed by the wall. The moisture regained by the wall will not only damp the indoor air, but also cause molding and peeling of the decorated wall.

\section{Solutions}

In terms of design, the government, industry, and enterprises should strengthen research and the compilation of the general-purpose drawing set. The drawing set should cover various types of RRB, and the design of the architectural style should be attempted based on the type and size of the family. In this way, it does not only ensure the valid functional space of RRB and meet the needs of different types of families, but also the structural safety and seismic performance of RRB; in addition, many problems of RRB can also be avoided.

In regard to construction, the government should train more qualified rural migrant workers. By training qualified rural migrant workers, it is possible to ensure the management and construction quality of RRB; on the other hand, it will help solve the unemployment issue of rural surplus labor. When the rural surplus labor is trained as qualified workers, the cost of self-constructed RRB will definitely drop.

For different types of RRB, while focusing on material and structural composition of thermal insulation layer, thermal insulation and energy-saving technologies should be developed for walls, roofs, doors, and windows. In consideration of the economy, applying mature thermal insulation and energy-saving technologies in RRB may help reduce energy dissipation and save heating costs for owners. These suggestions also offer solutions for the Chinese government to achieve the goal of "carbon peak" and 
"carbon neutralization." Increasing the application rate of clean and renewable energy in rural areas, including photovoltaic technology, ground source heat pumps, and biomass, may be beneficial. The key to a successful application of clean energy is reducing its cost. The support of government policies is also a critical factor.

For wall cracking, it is necessary to measure the width and depth of the crack as well as analyze the cause of the crack; then, effective measures should be taken to deal with it. Methods such as carbon fiber cloth repair, low pressure glue injection, and sealing after filling are all feasible. In regard to moisture regain, based on analyzing the reasons, the following two methods can be used: for traditional RRB, under the premise of good construction quality of the moisture barrier, existing moisture-proof measures can be utilized; for new types of RRB, such as light steel structure, above-ground foundation, such as screw piles, can be used to raise the foundation of RRB.

\section{Conclusion}

Based on the investigation data, this paper analyzes the problems existing in the architectural style, energy utilization and dissipation, design, construction, as well as the structural safety of RRB in Northwest China. In light of these problems, reasonable solutions have been suggested. The problems found and the solutions proposed have important reference value for the government, enterprises, universities, and scientific research institutes engaged in the design, construction, planning, and research of RRB. Follow-up work will first focus on the research of thermal insulation and energy-saving technologies of RRB. Second, with the government's cooperation, the training mode of rural migrant workers will be developed to improve the construction and management quality of RRB.

\section{Funding}

2021 Ministry of Housing and Urban-Rural Development Science and Technology Project (Project Number: 2021-k-154); Gansu Agricultural University Sheng Tongsheng Science and Technology Innovation Fund Project (Project Number: GSAU-STS-2018-33).

\section{Disclosure statement}

The authors declare no conflict of interest.

\section{Author contributions}

Zhaobo Zhang conceived the idea, performed the analytical work, and wrote the paper; Jianqiang Wang and Mao Hu performed the investigation.

\section{References}

[1] He C, Cui W, 2018, Rural Poverty Reduction Effect of Urbanization: Theoretical Mechanism and Empirical Test. Economic Science, 2018(4): 89-102.

[2] Wei L, Zhang J, 2018, The Evolution and Prospect of China's Rural Livelihood Policies in the Past 40 Years of Reform and Opening-Up: An Quantitative Analysis of Policy Texts Based on the No. 1 Central Documents. Journal of Lanzhou University, 2018(5): 91-101.

[3] Zhou L, Wu R, Dong Z, 2020, Investigation and reflection on Current Situation of Seismic Performance of Rural. Building Structure, 50(14): 86-90. 
[4] Liu H, 2016, Analysis on Floating Population's Housing in Super-Cities. Population, 219(38): 45-53.

[5] Wang L, Wang H, 2021, Chinese Rural Bed and Breakfast Design Under the Guidance of Regionalism. Architecture \& Culture, 2021(11): 40-42.

Publisher's note

Bio-Byword Scientific Publishing remains neutral with regard to jurisdictional claims in published maps and institutional affiliations. 